\title{
Voltammetric Determination of Captopril Using Chlorpromazine as a Homogeneous Mediator
}

\author{
Hossein Bahramipur and Fahimeh Jalali \\ Department of Chemistry, Razi University, Bagh Abrisham, Kermanshah 67149-67346, Iran \\ Correspondence should be addressed to Fahimeh Jalali, fahimehjalali@yahoo.com
}

Received 6 August 2011; Accepted 22 August 2011

Academic Editor: Jay D. Wadhawan

Copyright ( $) 2011$ H. Bahramipur and F. Jalali. This is an open access article distributed under the Creative Commons Attribution License, which permits unrestricted use, distribution, and reproduction in any medium, provided the original work is properly cited.

Chlorpromazine was used as a homogeneous electrocatalyst in the oxidation of captopril. The anodic peak current of chlorpromazine was increased substantially in the presence of low concentrations of captopril ( $\mathrm{pH} 4$ ). Cyclic voltammetry and chronoamperometry were used to study the kinetics of the catalytic electron transfer reaction. The values of electron transfer coefficient $(\alpha)$ and catalytic rate constant $\left(k_{\text {cat }}\right)$ were estimated to be 0.34 and $8.48 \times 10^{2} \mathrm{M}^{-1} \mathrm{sec}^{-1}$, respectively. Linear sweep voltammetry was used for the determination of captopril in the presence of chlorpromazine. A linear calibration curve was obtained in the concentration range of captopril of $10.0-300.0 \mu \mathrm{M}$, with a limit of detection of $3.65 \mu \mathrm{M}$. The relative standard deviation (RSD\%) for 5 replicate measurements of captopril $(100 \mu \mathrm{M})$ was $1.96 \%$. The method was applied to the determination of captopril in pharmaceutical formulations and blood serum samples with satisfactory results.

\section{Introduction}

Captopril (CAP), 1-(3-mercapto-2-D-methyl-1-oxopropyl) proline (Scheme 1(a)), is an oral drug and a member of a class of drugs called angiotensin-converting enzyme (ACE) inhibitors. CAP has been widely used as antihypertensive drug and to moderate heart failure [1]. It normally works by lowering blood levels of angiotensin enzyme, to help relax the blood vessels and lower blood pressure. Relaxing the arteries, and as a consequence lowering of blood pressure, improves the pumping efficiency of a failing heart and improves cardiac output in patients with heart failure [2]. CAP with a thiol functional group may also act as a scavenger of free radicals in living systems [3-5].

Several methods have been applied to the determination of CAP, including high-performance liquid chromatography [6-9], gas chromatography $[10,11]$, spectrophotometry $[12$, 13], fluorimetry [14-16], radioimmunoassay [17], chemiluminescence [18-20], atomic absorption spectrophotometry [21], Raman spectroscopy [22], capillary electrophoresis [23, 24], and electrochemical methods [25-30].
Direct electrochemical determination of pharmaceutical compounds has a number of limitations, such as low sensitivity and reproducibility, slow electron transfer kinetics, and high overpotentials. The chemical modifications with redox active materials (homogenous and heterogeneous catalysts) offer significant advantages in the design and development of electrochemical sensors. During the reaction, the mediator shuttles electrons between the analyte and the electrode with significant reduction in the activation overpotential.

In this study, chlorpromazine (CPZ, Scheme 1(b)), an antipsychotic drug, was used as a suitable homogeneous mediator in the electrooxidation of CAP. The proposed method was fast, selective, sensitive, and successful in the determination of CAP in real samples. Cyclic voltammetry (CV) and chronoamperometry were used to characterize the electrochemical properties of $\mathrm{CPZ}$ and to investigate its electrocatalytic effect on the CAP oxidation. Kinetic parameters such as electron transfer coefficient and the rate constant of catalytic reaction were estimated. 
<smiles>CC(CS)C(=O)N1CCCC1C(=O)O</smiles>

(a)<smiles>CN(C)CCCN1c2ccccc2SC2C=CC=CC21</smiles>

(b)

Scheme 1: Chemical structures of (a) captopril and (b) chlorpromazine.

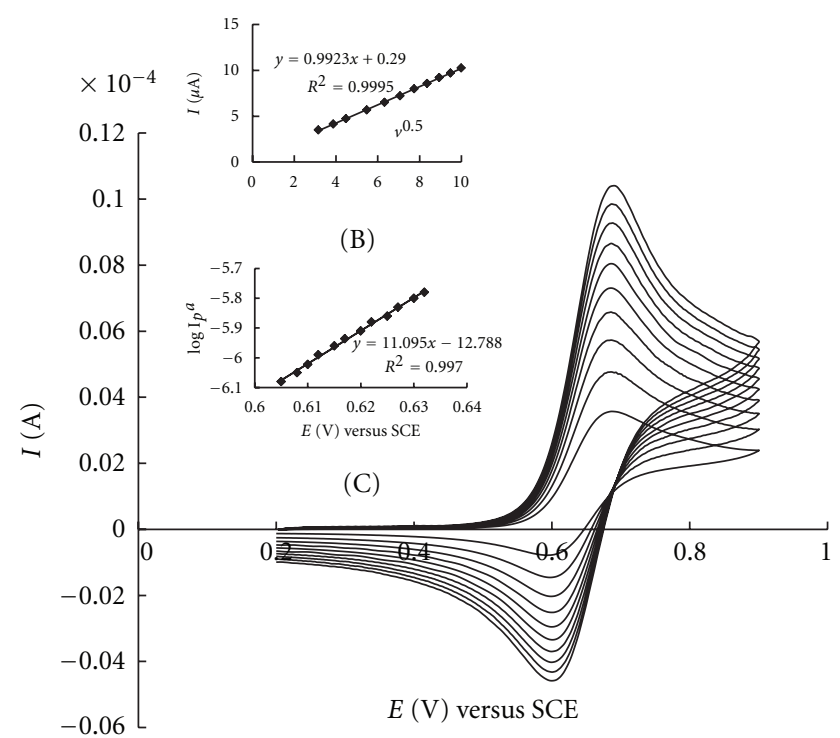

(A)

Figure 1: (A) Cyclic voltammograms of chlorpromazine (1.5 mM) at a GCE and various scan rates; from bottom to top: 5, 10, 20, 30, $40,50,60,70,80,90$, and $100 \mathrm{mV} \mathrm{s}^{-1}$ in phosphate buffer solution (pH 4.0, 0.04 M). (B) Plot of $i_{p}^{a}$ versus $\nu^{1 / 2}$. (C) Tafel plot.

\section{Experimental}

2.1. Reagents. CPZ hydrochloride was purchased from Merck and CAP was from Sigma. All solutions were prepared from analytical reagent grade chemicals and were used as received from the suppliers without further purification. Doubly distilled water was used for the preparation of solutions. All experiments were carried out at ambient temperature $\left(25^{\circ} \mathrm{C}\right)$. The CAP tablets $(25 \mathrm{mg}$ and $50 \mathrm{mg}$ per tablets) were from Tehran Darou Co. (Tehran, Iran), and Iran Daru Co. (Tehran, Iran), respectively. A freshly prepared $10.0 \mathrm{mM}$ aqueous solution of CAP was used for the preparation of more dilute solutions. The stock solution was kept in refrigerator at $4^{\circ} \mathrm{C}$ in the dark.

2.2. Apparatus. Electrochemical measurements were performed using a Micro-Autolab ( $\mu 3$ AUT-70751), potentiostat/galvanostat instrument connected to a three-electrode



Figure 2: Cyclic voltammograms of a: phosphate buffer solution $(\mathrm{pH} 4.0,0.05 \mathrm{M}), \mathrm{b}: \mathrm{a}+0.5 \mathrm{mM}$ CAP, $\mathrm{c}: \mathrm{a}+0.5 \mathrm{mM} \mathrm{CPZ}$, and $\mathrm{d}: \mathrm{c}$ $+0.5 \mathrm{mM}$ CAP. Scan rate $50 \mathrm{mV} \mathrm{s}^{-1}$ at the GCE.

cell. The electrochemical data acquisition was performed using the software NOVA 1.6. A conventional three-electrode cell was used containing a glassy carbon disk electrode (GCE) as the working electrode, and a Pt wire was directly immersed in the solution as the auxiliary electrode and a saturated calomel electrode (SCE) as the reference electrode. The geometrical area of the glassy carbon electrode was $0.0314 \mathrm{~cm}^{2}$. A Metrohm $781 \mathrm{pH} /$ ion meter was used for $\mathrm{pH}$ measurements.

2.3. Preparation of Real Samples. Ten tablets of CAP $(25$ or $50 \mathrm{mg}$ per tablets) were completely ground, and $10 \mathrm{mg}$ of the fine powder was accurately weighed and dissolved in $10 \mathrm{~mL}$ of phosphate buffer solution $(0.05 \mathrm{M}, \mathrm{pH} 4)$ using ultrasonication $(30 \mathrm{~min})$. The blood serum sample was centrifuged and the supernatant was diluted 50 times with water without any further pretreatment. The standard addition method was used for the determination of CAP in both kinds of real samples.

2.4. General Procedure. The GCE was polished with an alumina fine powder $(0.05 \mu \mathrm{m})$ in a water slurry using a polishing cloth followed by rinsing thoroughly with distilled 


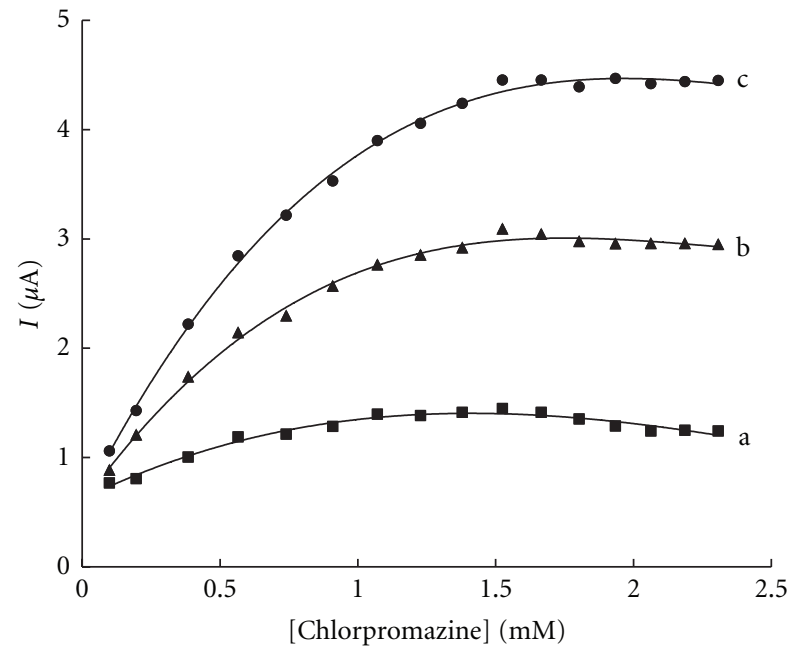

FIgURE 3: Effect of CPZ concentration on the anodic peak current of CAP. [CAP]: a: $0.1 \mathrm{mM}$, b: $0.25 \mathrm{mM}$, and c: $0.5 \mathrm{mM}$. Scan rate $50 \mathrm{mV} \mathrm{s}^{-1} ; \mathrm{pH} 4.0$.

water. In a typical experiment, the electrodes were immersed in a solution containing $1.5 \mathrm{mM} \mathrm{CPZ}$ and phosphate buffer $(\mathrm{pH} 4.0,0.05 \mathrm{M})$. The potential was swept from +0.2 to $+0.9 \mathrm{~V}$ versus SCE with a scan rate of $50 \mathrm{mV} \mathrm{s}^{-1}$. The experiment was repeated in the presence of CAP as the sample solution.

\section{Results and Discussion}

3.1. Electrochemical Oxidation of $C P Z$ at the GCE. The electrochemical behavior of $\mathrm{CPZ}$ was studied by cyclic voltammetry, and the results obtained were similar to previous reports [31]. Figure 1 shows the cyclic voltammograms of a $1.5 \mathrm{mM} \mathrm{CPZ}$ solution at the surface of GCE and different scan rates $(\mathrm{pH} 4)$. $\mathrm{CPZ}$ shows a redox couple at about +0.60 and $+0.69 \mathrm{~V}$ versus SCE at the experimental conditions. The values of half-wave potential $\left[E_{1 / 2}=\left(E_{p}^{a}+E_{p}^{c}\right) / 2\right]$ and peak potential separation $\left(\Delta E_{p}=E_{p}^{a}-E_{p}^{c}\right)$ are about 0.64 and $0.09 \mathrm{~V}$ at scan rate of $10 \mathrm{mV} \mathrm{s}^{-1}$, respectively. The value of $\Delta E_{p}$ corresponds to a one-electron quasireversible process which can be represented as follows.

Scheme 1 (oxidation of $\mathrm{CPZ}$ ).

$$
\mathrm{CPZ} \longrightarrow \mathrm{CPZ}^{+}+\mathrm{H}^{+}+\mathrm{e}
$$

where $\mathrm{CPZ}^{+}$refers to the $\mathrm{CPZ}$ cation radical.

Both anodic and cathodic peak currents increased along with the increase in scan rate (Figure 1(A)). The plot of anodic peak current versus square root of sweep rate (10$100 \mathrm{mV} \mathrm{s}^{-1}$ ) was linear (Figure 1(B)) which suggests a simple diffusion-controlled mechanism. The results of polarization studies (Figure $1(\mathrm{C})$ ) showed that the average Tafel [32] slope, $n(1-\alpha) F / 2.3 \mathrm{RT}$, was $89.5 \mathrm{mV}$. Assuming the rate determining step involves a one-electron process $(n=1)$,



(A)

Figure 4: (A) Cyclic voltammograms of CPZ solution ( $1.5 \mathrm{mM})$ on a GCE and in the presence of CAP $(0.5 \mathrm{mM})$ at various scan rates; from bottom to top: $20,30,40,50,60,70,80,90$, and $100 \mathrm{mV} \mathrm{s}^{-1}$ in phosphate buffer solution ( $\mathrm{pH} 4.0,0.05 \mathrm{M}$ ). (B) Plot of $i_{p}^{a}$ versus $\nu^{1 / 2}$. (C) Plot of normalized anodic peak current versus $\nu$.

a value of 0.34 is obtained for the charge transfer coefficient $(\alpha)$ of the redox reaction in Scheme 1.

The study of the effect of $\mathrm{pH}$ on the voltammetric response of $\mathrm{CPZ}$ revealed that the system shows more reversibility in acidic solutions, and a sodium phosphate buffer with $\mathrm{pH} 4$ was selected as a proper medium in further studies.

3.2. Electrocatalytic Behavior of $C P Z$ towards CAP. Figure 2 shows the electrocatalytic oxidation of CAP in the presence of CPZ at a GCE surface. As is obvious, at the potential range studied (0.2-1.0 V), CAP was not electroactive (Figure 2(b)). On the other hand, the anodic current of $\mathrm{CPZ}$ was increased substantially in the presence of low concentrations of CAP (Figures 2(c) and 2(d)). This observation is an evidence for electrocatalytic oxidation of CAP by CPZ. The electrocatalytic activity of CPZ was reported in previous reports [33].

The mechanism of $\mathrm{EC}^{\prime}$ reaction could be represented as follows [34].

Scheme 2 (electrocatalytic effect of $\mathrm{CPZ}$ on the oxidation of CAP).

$$
\begin{gathered}
\mathrm{CPZ} \longrightarrow \mathrm{CPZ}^{+}+\mathrm{H}^{+}+\mathrm{e} \\
\mathrm{CPZ}^{+}+\mathrm{CAP}(\text { red }) \longrightarrow \mathrm{CPZ}+\mathrm{CAP}(\text { ox }) .
\end{gathered}
$$

The influence of $\mathrm{CPZ}$ concentration on the electrocatalytic peak current was studied at three different concentrations of CAP (Figures 3(a)-3(c)) at $\mathrm{pH} 4.0$, and in the range of 0.10 to $2.40 \mathrm{mM} \mathrm{CPZ}$. The results showed that by increasing the concentration of $\mathrm{CPZ}$ up to $1.55 \mathrm{mM}$ the peak 


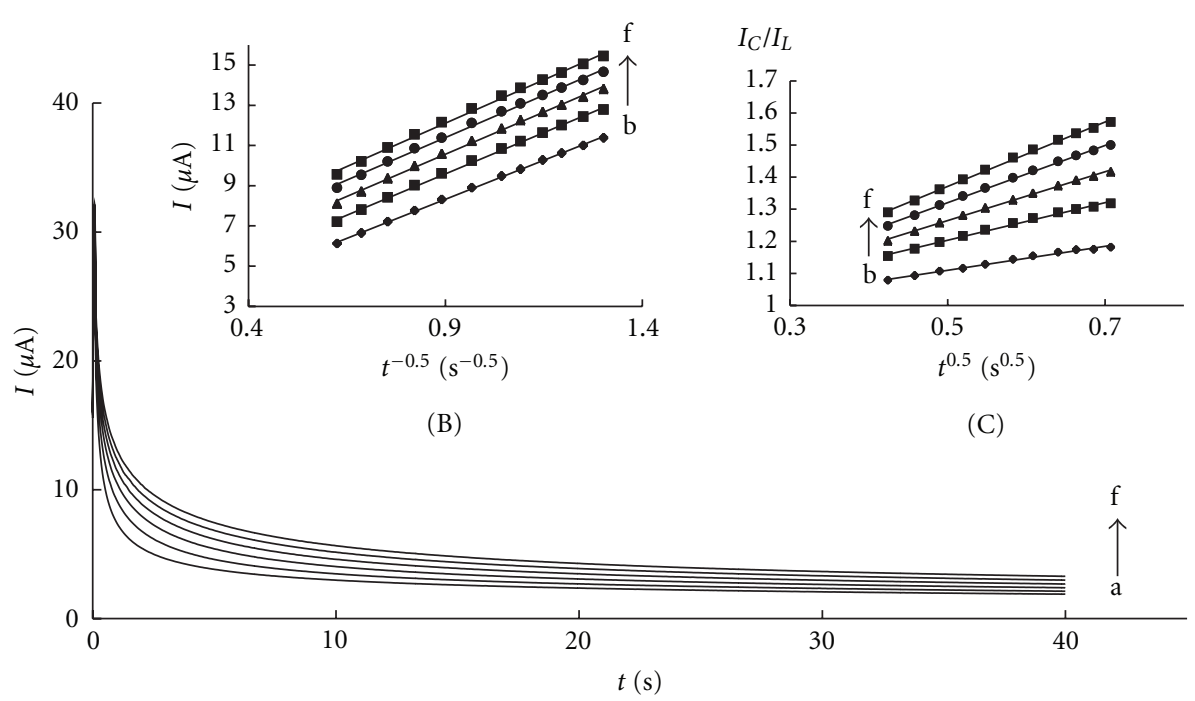

(A)

Figure 5: (A) Chronoamperometric responses of a GCE in a phosphate buffer solution ( $\mathrm{pH} 4.0,0.05 \mathrm{M})+1.50 \mathrm{mM} \mathrm{CPZ}$ and different amounts of CAP: a: $0.0 \mathrm{mM}$; b: $0.1 \mathrm{mM}$; c: $0.2 \mathrm{mM}$; d: $0.3 \mathrm{mM}$; e: $0.4 \mathrm{mM}$; f: $0.5 \mathrm{mM}$. (B) Plots of currents versus the square root of time elapsed $\left(t^{0.5}\right)$ for the chronoamperograms in (A) b to f. (C) Plots of $I_{C} / I_{L}$ versus square root of time elapsed $\left(t^{0.5}\right)$ for the chronoamperograms in (A) b to $f$. The step potential was $+0.850 \mathrm{~V}$ versus SCE.

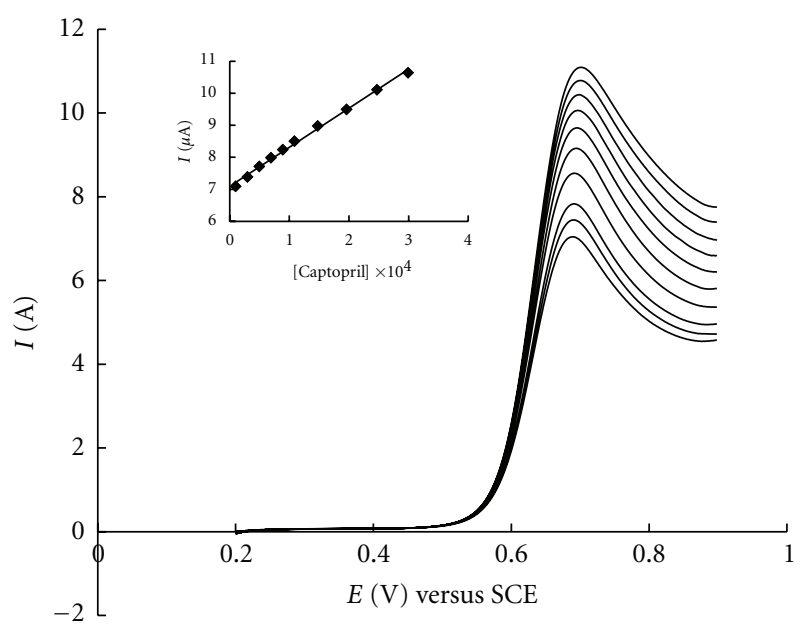

FIGURE 6: Linear sweep voltammograms for different concentrations of CAP; from bottom to top: 0.010, 0.030, 0.050, 0.070, 0.089, $0.110,0.150,0.200,0.250,0.300 \mathrm{mM}$. [CPZ] $=0.5 \mathrm{mM} ; \mathrm{pH}=4$; scan rate of $50 \mathrm{mV} \mathrm{s}^{-1}$.

current increased, whereas higher concentrations of $\mathrm{CPZ}$ caused a slight decrease on the magnitude of peak current, which may be due to the formation of CPZ aggregates. Therefore, $1.50 \mathrm{mM} \mathrm{CPZ} \mathrm{concentration} \mathrm{was} \mathrm{selected} \mathrm{for}$ further studies.

The scan rate dependence of cyclic voltammograms of a CAP solution $(0.5 \mathrm{mM})$ in the presence of CPZ $(1.50 \mathrm{mM})$ was studied (Figure 4(A)) at a GCE surface. Figure 4(B) shows that the anodic peak current increases linearly with the square root of the sweep rate as expected for a diffusioncontrolled reaction. The regression equation is $I_{P}^{a}(\mu \mathrm{A})=$
$1.2 v^{1 / 2}(\mathrm{mV} / \mathrm{s})^{0.5}+3.43$ with $R^{2}=0.9957$. A plot of the scan rate-normalized $\operatorname{current}\left(I_{P} / \nu^{1 / 2}\right)$ versus sweep rate (Figure 4(C)) exhibits the characteristic shape typical of an $\mathrm{EC}^{\prime}$ process [32].

3.3. Chronoamperometric Studies. In order to obtain an estimation of the rate constant of the catalytic oxidation of CAP $\left(k_{\text {cat }}\right)$, chronoamperometric method was applied to the system. The chronoamperograms obtained for a series of CAP solutions (with a step potential of $+0.850 \mathrm{~V}$ versus SCE) are shown in Figure 5(A). Using the Cottrell equation (3) [33] it can be seen that the plot of $i$ versus $t^{-1 / 2}$ under diffusion-controlled conditions is linear (Figure 5(B))

$$
i=\frac{n \mathrm{FAD}^{1 / 2} c}{(\pi t)^{1 / 2}}
$$

where $c$ is the concentration of CAP in $\mathrm{mol} / \mathrm{cm}^{3}$ and $t$ is the time elapsed in seconds.

The rate constant for the chemical reaction between CPZ and CAP $\left(k_{\text {cat }}\right)$ is determined according to the method described in the literature $[30,34,35]$ by chronoamperometry using (4)

$$
I_{C} / I_{L}=\pi^{1 / 2} \gamma^{1 / 2}=\pi^{1 / 2}\left(k_{\mathrm{cat}} c t\right)^{1 / 2}
$$

where $I_{C}$ is the catalytic current of $\mathrm{CPZ}$ in the presence of CAP and $I_{L}$ is the limiting current in the absence of CAP.

From the slope of $I_{C} / I_{L}$ versus $t^{1 / 2}$ for five different concentrations of CAP, the average value of $k_{\text {cat }}$ was calculated to be $8.48 \times 10^{2} \mathrm{M}^{-1} \mathrm{sec}^{-1}$ (Figure $5(\mathrm{C})$ ). This value of rate constant explains the sharp catalytic peak observed for the oxidation of CAP at the surface of GCE. 


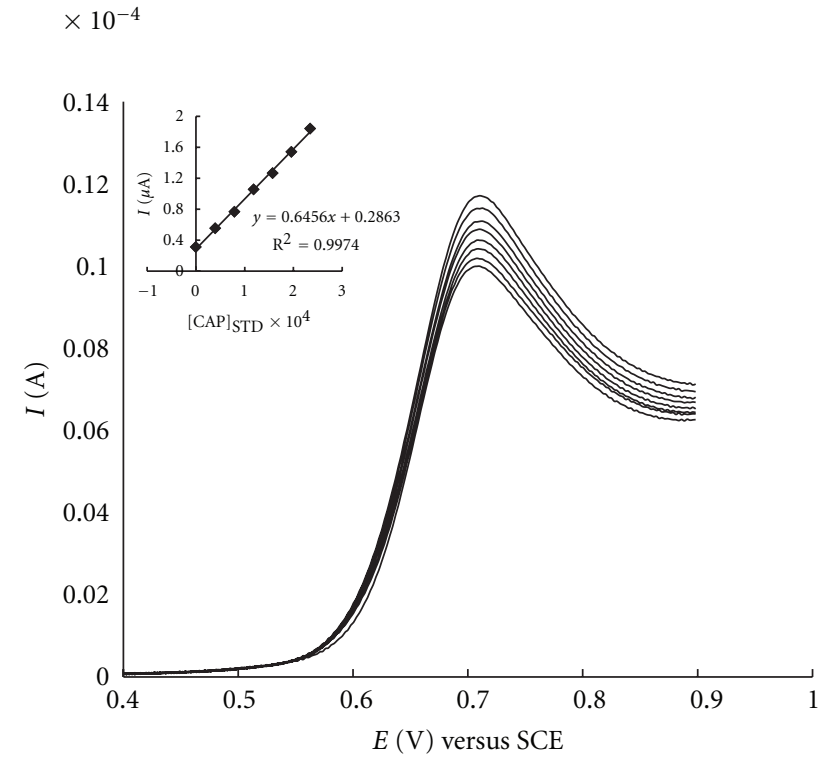

Figure 7: Linear sweep voltammograms and standard addition plot (inset) for the determination of CAP in blood serum sample. The concentration of spiked CAP was $5.0 \times 10^{-5} \mathrm{M}$, and the peak current of $\mathrm{CPZ}$ is subtracted from all peak currents in the presence of CAP. Experimental conditions are as Figure 6.

3.4. Determination of CAP by Its Electrocatalytic Oxidation in the Presence of CPZ. Linear sweep voltammetry (LSV) was used for construction of a calibration plot for CAP in a concentration range of $10.0-300.0 \mu \mathrm{M}$ under the optimum conditions and a scan rate of $50 \mathrm{mV} \mathrm{s}^{-1}$ (Figure 6). The regression line (inset) equation was $i_{p}^{a}=8 \times 10^{-6} c+0.01$ with $R^{2}=0.997$. The limit of detection $\left(3 s_{b} / m\right.$, where $s_{b}$ is the standard deviation of the blank signal and $m$ is the slope of the calibration curve) equals $3.65 \mu \mathrm{M}$ CAP. The relative standard deviation (\%R.S.D.) for 5 replicate measurements of $100 \mu \mathrm{M}$ CAP was $1.96 \%$.

The method was applied to the determination of CAP in pharmaceutical preparations (tablets) and biological fluids (spiked blood serum samples) using standard addition technique (Figure 7). As is obvious from Table 1, the results of the proposed voltammetric method, compared to labelled or spiked amounts of CAP, are quite satisfactory.

\section{Conclusions}

In the present work, chlorpromazine was used as a redox mediator for the homogeneous electrocatalytic oxidation of captopril in aqueous media $(\mathrm{pH} 4)$ at the surface of a glassy carbon electrode. The electrochemical characteristics of chlorpromazine and its catalytic effect on the oxidation of captopril were investigated. The rate constant of the catalytic reaction was estimated using chronoamperometry.

Linear sweep voltammetry was successfully applied to the determination of captopril in the presence of an optimum concentration of chlorpromazine at $\mathrm{pH}$ 4. The results of the determination of captopril in its tablets as well as blood serum samples spiked with low concentrations of the drug
TABLE 1: Determination of captopril in formulations and blood serum samples.

\begin{tabular}{lccc}
\hline Sample & $\begin{array}{r}\text { Labelled or } \\
\text { added }(\mu \mathrm{M})\end{array}$ & Found $^{\mathrm{a}}(\mu \mathrm{M})$ & Recovery $\left.^{\mathrm{a}} \%\right)$ \\
\hline 50 mg tablet & 50 & $\begin{array}{c}52.36 \\
( \pm 0.4)\end{array}$ & 104.72 \\
25 mg tablet & 50 & $\begin{array}{c}50.32 \\
( \pm 0.2)\end{array}$ & 100.65 \\
Blood serum & $50^{\mathrm{b}}$ & $\begin{array}{c}50.51 \\
( \pm 2.8)\end{array}$ & 101.01 \\
\hline
\end{tabular}

${ }^{a}$ Mean value of three replicate determinations. Values in the parentheses are RSD\%.

${ }^{\mathrm{b}}$ Amount of CAP in diluted (50 times) blood serum samples.

were satisfactory. The proposed electrochemical method was simple, fast, and selective without the need for electrode modification.

\section{References}

[1] K. Forey, Ed., Analytical Profiles of Drugs Substances, vol. 11, Academic Press, New York, NY, USA, 1982.

[2] J. Koch-Weser, "Angiotensin converting-enzyme inhibitor in refractory hypertension," The New England Journal of Medicine, vol. 299, no. 7, pp. 363-364, 1978.

[3] N. Aykin, R. Neal, M. Yusof, and N. Ercal, "Determination of captopril in biological samples by high-performance liquid chromatography with ThiGlo3 derivatization," Biomedical Chromatography, vol. 15, no. 7, pp. 427-432, 2001.

[4] A. M. Pimenta, A. N. Araújo, and M. C. B. S. M. Montenegro, "Sequential injection analysis of captopril based on colorimetric and potentiometric detection," Analytica Chimica Acta, vol. 438, no. 1-2, pp. 31-38, 2001.

[5] T. Mirza and H. S. Tan, "Determination of captopril in pharmaceutical tablets by anion-exchange HPLC using indirect photometric detection; a study in systematic method development," Journal of Pharmaceutical and Biomedical Analysis, vol. 25, no. 1, pp. 39-52, 2001.

[6] J. Russell, J. A. McKeown, C. Hensman, W. E. Smith, and J. Reglinski, "HPLC determination of biologically active thiols using pre-column derivatisation with 5,5'-dithio-(bis-2nitrobenzoic acid)," Journal of Pharmaceutical and Biomedical Analysis, vol. 15, no. 11, pp. 1757-1763, 1997.

[7] M. Amini, A. Zarghi, and H. Vatanpour, "Sensitive highperformance liquid chromatographic method for determination of captopril in plasma," Pharmaceutica Acta Helvetiae, vol. 73, no. 6, pp. 303-306, 1999.

[8] A. Khedr and H. El-Sherief, "3-bromomethyl-propyphenazone as a new derivatization reagent for high performance liquid chromatography of captopril and hydrochlorothiazide with UV- detection," Biomedical Chromatography, vol. 12, no. 2, pp. 57-60, 1998.

[9] M. Bahmaei, A. Khosravi, C. Zamiri, A. Massoumi, and M. Mahmoudian, "Determination of captopril in human serum by high performance liquid chromatography using solidphase extraction," Journal of Pharmaceutical and Biomedical Analysis, vol. 15, no. 8, pp. 1181-1186, 1997.

[10] T. Ito, Y. Matsuki, H. Kurihara, and T. Nambara, "Sensitive method for determination of captopril in biological fluids by gas chromatography-mass spectrometry," Journal of Chromatography, vol. 417, no. 1, pp. 79-87, 1987. 
[11] Y. C. Liu, H. L. Wu, H. S. Kou, S. H. Chen, and S. M. $\mathrm{Wu}$, "Derivatization-gas chromatographic determination of Captopril,” Analytical Letters, vol. 28, pp. 1465-1481, 1995.

[12] K. M. .Emara K.M., H. F. Askal, and G. A. Saleh, "Spectrophotometric determination of tetracycline and oxytetracycline in pharmaceutical preparations," Talanta, vol. 38, no. 11, pp. 1219-1222, 1991.

[13] H. Kadin and R. B. Poet, "Sequential electrochemical reduction, solvent partition, and automated thiol colorimetry for urinary captopril and its disulfides," Journal of Pharmaceutical Sciences, vol. 71, no. 10, pp. 1134-1138, 1982.

[14] K. Imai, T. Toyo'oka, and Y. Watanabe, "A novel fluorogenic reagent for thiols: ammonium 7-fluorobenzo-2-oxa-1,3diazole-4-sulfonate," Analytical Biochemistry, vol. 128, no. 2, pp. 471-473, 1983.

[15] S. M. Al-Ghannam, A. M. El-Brashy, and B. S. Al-Farhan, "Fluorimetric determination of some thiol compounds in their dosage forms," Farmaco, vol. 57, no. 8, pp. 625-629, 2002.

[16] Y. Chen and R. Cai, "Study and analytical application of inhibitory effect of captopril on multienzyme redox system," Talanta, vol. 61, no. 6, pp. 855-861, 2003.

[17] K. K. Wong, S. Lan, and B. H. Migdalof, "In vitro biotransformations of [14C]captopril in the blood of rats, dogs and humans," Biochemical Pharmacology, vol. 30, no. 19, pp. 26432650, 1981.

[18] X. R. Zhang, W. R. G. Baeyens, G. Van Der Weken, A. C. Calokerinos, and K. Nakashima, "Chemiluminescence determination of captopril based on a Rhodamine B sensitized cerium(IV) method," Analytica Chimica Acta, vol. 303, no. 1, pp. 121-125, 1995.

[19] A. Economou, D. G. Themelis, G. Theodoridis, and P. D. Tzanavaras, "Sensitive determination of captopril by flow injection analysis with chemiluminescence detection based on the enhancement of the luminol reaction," Analytica Chimica Acta, vol. 463, no. 2, pp. 249-255, 2002.

[20] J. A. M. Pulgarín, L. F. G. Bermejo, and P. F. López, "Sensitive determination of captopril by time-resolved chemiluminescence using the stopped-flow analysis based on potassium permanganate oxidation," Analytica Chimica Acta, vol. 546, no. 1, pp. 60-67, 2005.

[21] M. A. El Reis, F. M. Abou Attia, and I. M. M. Kenawy, "Indirect determination of captopril by AAS," Journal of Pharmaceutical and Biomedical Analysis, vol. 23, no. 2-3, pp. 249-254, 2000.

[22] S. Mazurek and R. Szostak, "Quantitative determination of captopril and prednisolone in tablets by FT-Raman spectroscopy," Journal of Pharmaceutical and Biomedical Analysis, vol. 40, no. 5, pp. 1225-1230, 2006.

[23] S. Hillaert and W. Van Den Bossche, "Determination of captopril and its degradation products by capillary electrophoresis," Journal of Pharmaceutical and Biomedical Analysis, vol. 21, no. 1, pp. 65-73, 1999.

[24] T. Pérez-Ruiz, C. Martínez-Lozano, and R. Galera, "Development and validation of a capillary electrophoresis method with laser-induced fluorescence detection for the determination of captopril in human urine and pharmaceutical preparations," Electrophoresis, vol. 27, no. 12, pp. 2310-2316, 2006.

[25] R. I. Stefan, J. F. van Staden, and H. Y. Aboul-Enein, "An amperometric biosensors/SIA system for the simultaneous determination of S- and R-captopril," Biosensors and Bioelectronics, vol. 15, no. 1-2, pp. 1-5, 2000.

[26] X. Ioannides, A. Economou, and A. Voulgaropoulos, "A study of the determination of the hypertensive drug captopril by square wave cathodic adsorptive stripping voltammetry,"
Journal of Pharmaceutical and Biomedical Analysis, vol. 33, no. 2, pp. 309-316, 2003.

[27] B. Rezaei and S. Damiri, "Voltammetric behavior of multiwalled carbon nanotubes modified electrode-hexacyanoferrate(II) electrocatalyst system as a sensor for determination of captopril," Sensors and Actuators, B, vol. 134, no. 1, pp. 324331, 2008.

[28] H. Karimi-Maleh, A. A. Ensafi, and A. R. Allafchian, "Fast and sensitive determination of captopril by voltammetric method using ferrocenedicarboxylic acid modified carbon paste electrode," Journal of Solid State Electrochemistry, vol. 14, no. 1, pp. 9-15, 2010.

[29] M. A. Khalilzadeh, H. Karimi-Maleh, A. Amiri, F. Gholami, and R. M. mazhabi, "Determination of captopril in patient human urine using ferrocenemonocarboxylic acid modified carbon nanotubes paste electrode," Chinese Chemical Letters, vol. 21, no. 12, pp. 1467-1470, 2010.

[30] M. Fouladgar, "Electrocatalytic measurement of trace amount of captopril using multiwall carbon nanotubes as a sensor and ferrocene as a mediator," International Journal of Electrochemical Science, vol. 6, no. 3, pp. 705-716, 2011.

[31] K. Takamura, S. Inoue, F. Kusu, and N. Oyama, "Electrocatalytic oxidation of chlorpromazine in phosphate solution," Bulletin of the Chemical Society of Japan, vol. 58, no. 3, pp. 987990, 1985.

[32] A. Bard and L. Folkner, Electrochemical Methods: Principles and Applications, John Wiley \& Sons, New York, NY, USA, 2nd edition, 2001.

[33] A. Salimi, S. Lasghari, and A. Noorbakhash, "Carbon nanotubes-ionic liquid and chloropromazine modified electrode for determination of $\mathrm{NADH}$ and fabrication of ethanol biosensor," Electroanalysis, vol. 22, no. 15, pp. 1707-1716, 2010.

[34] M. Mazloum-Ardakani, H. Beitollahi, B. Ganjipour, H. Naeimi, and M. Nejati, "Electrochemical and catalytic investigations of dopamine and uric acid by modified carbon nanotube paste electrode," Bioelectrochemistry, vol. 75, no. 1, pp. 1$8,2009$.

[35] Z. Galus, Fundumentals of Electrochemical Analysis, Ellis Horwood, New York, NY, USA, 1976. 




International Journal of

Medicinal Chemistry

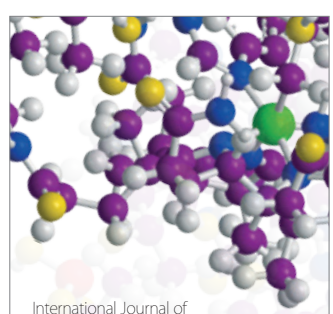

Carbohydrate Chemistry

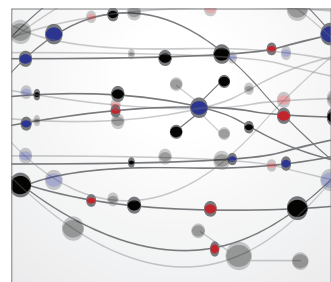

The Scientific World Journal
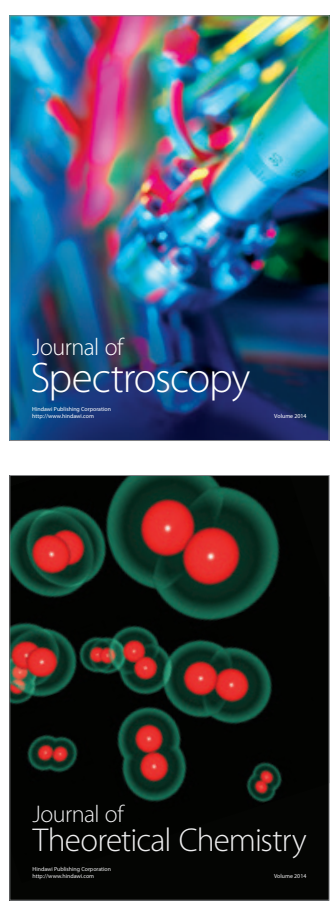
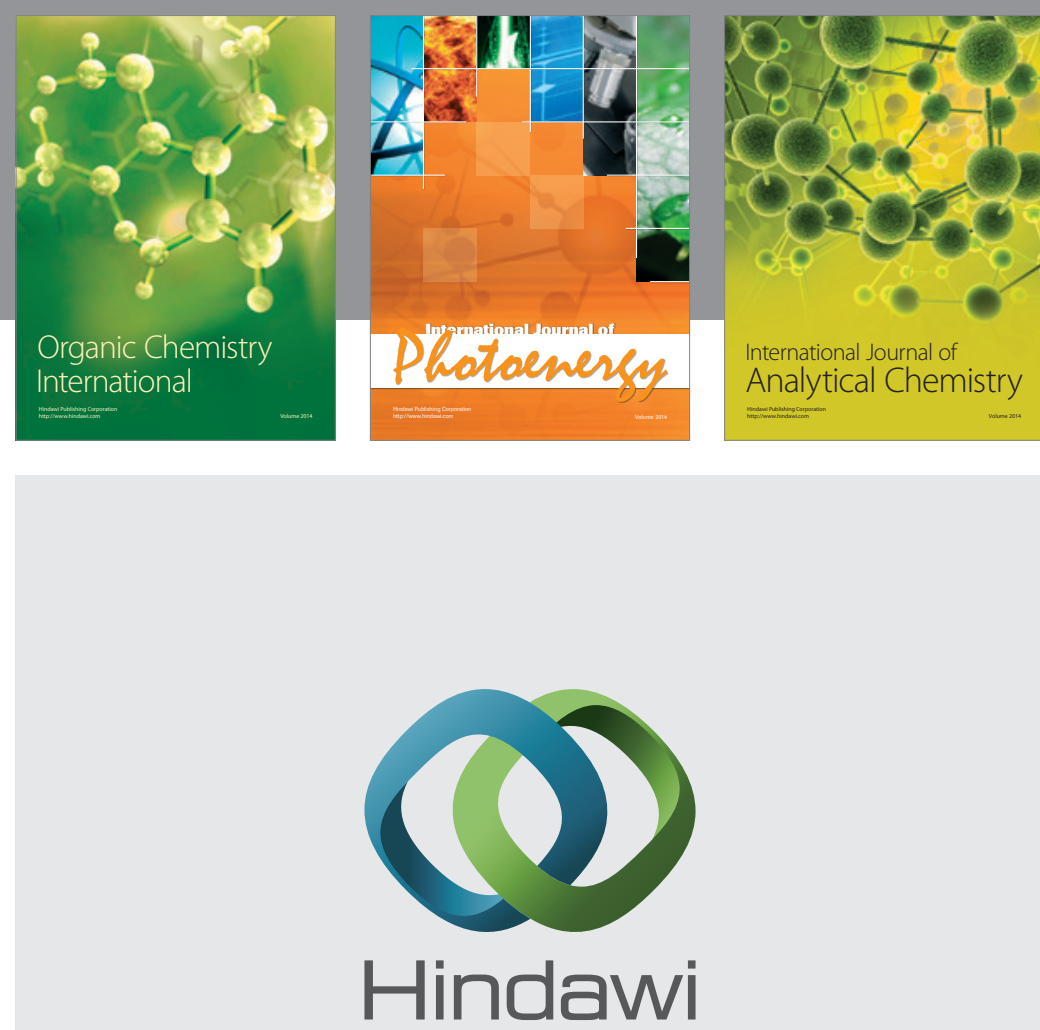

Submit your manuscripts at

http://www.hindawi.com
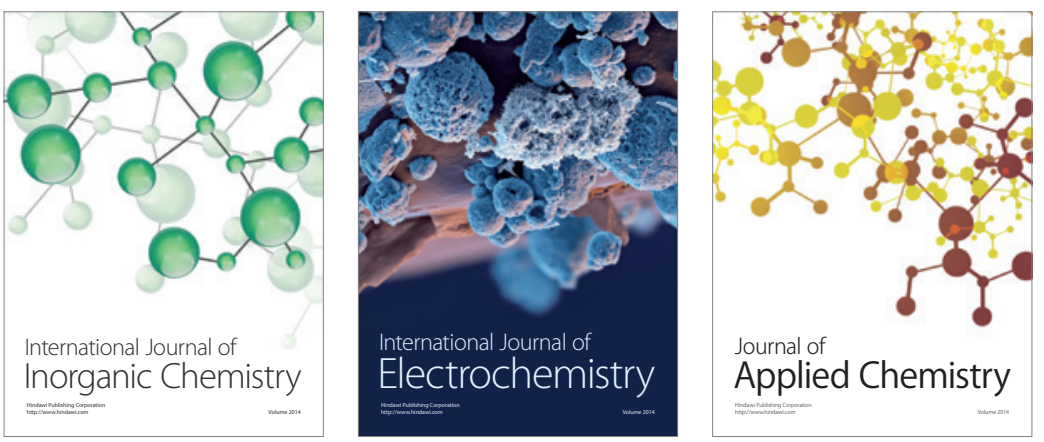

Journal of

Applied Chemistry
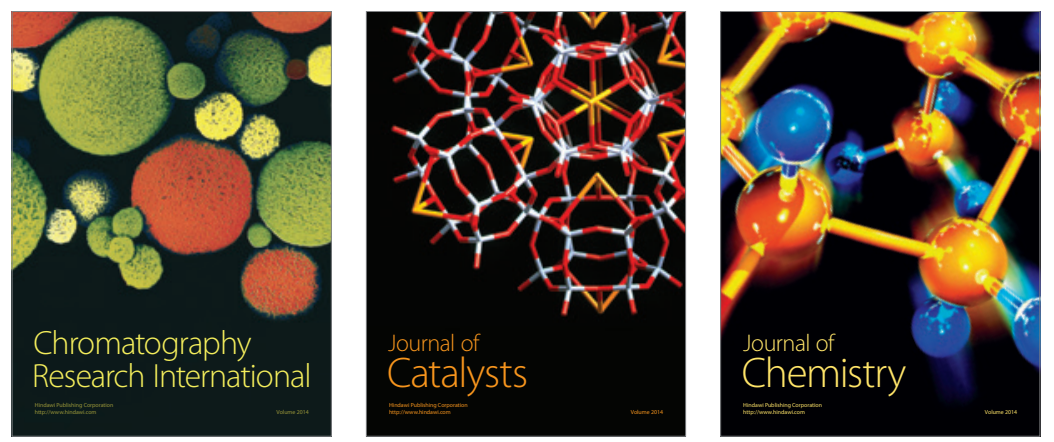
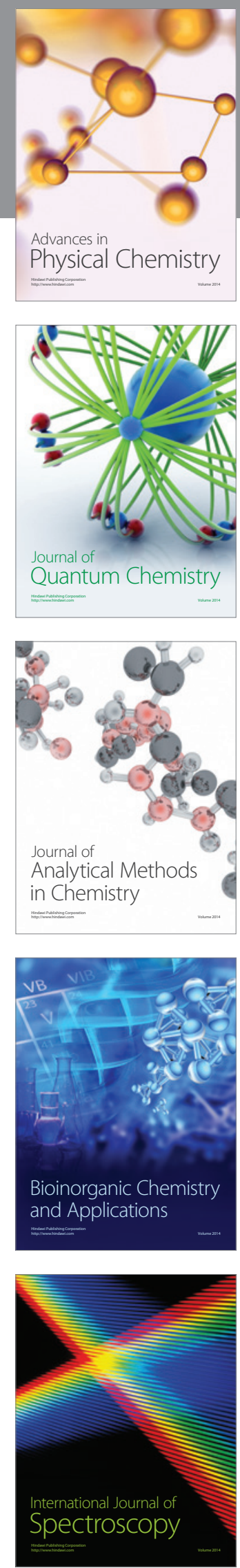